\title{
Three-dimensional distribution of $S$ wave reflectors in the northern Kinki district, southwestern Japan
}

\author{
Sho Aoki ${ }^{*}$, Yoshihisa lio, Hiroshi Katao, Tsutomu Miura, Itaru Yoneda and Masayo Sawada
}

\begin{abstract}
Distinct reflected waves $(S \times S$ ) are observed in the northern Kinki district, southwestern Japan. We conducted a highresolution reflection analysis by using data from 128 seismic stations with an average spacing of about $5 \mathrm{~km}$. We used a stacking method to obtain three-dimensional distributions of relative reflection strengths of $S$ waves and found a thin planar zone of high reflection strengths at depths of $25-30 \mathrm{~km}$, which we call a S wave reflector. We also found that the zone of high reflection strengths is dipping to the north and that low-frequency earthquakes (LFEs) occurred near the edge of the zone at depths around the Moho discontinuity. It is inferred from these results that fluid is concentrated in this zone of high reflection strengths. It is likely that the zone of high reflection strengths is a path of fluid upwelling from the mantle, together with the hypocentral region of LFEs, that is located near the lower edge of the zone. The northern Kinki district is thought to be part of the Niigata-Kobe Tectonic Zone (NKTZ) high strain rates region. The high reflection strengths zone may be associated with high strain rates in the NKTZ.
\end{abstract}

Keywords: Reflection analysis, Niigata-Kobe Tectonic Zone, Fluid, S wave reflector

\section{Introduction}

In the northern Kinki district, southwestern (SW) Japan, the Philippine Sea plate subducts beneath the overriding Eurasian plate, and there are no active volcanoes. This district is also characterized by high strain rates and is thought to be part of the Niigata-Kobe Tectonic Zone (NKTZ; Sagiya et al. 2000) as shown in Fig. 1. Microearthquake activity continuously occurs in this district, in particular north of the Arima-Takatsuki Tectonic Line (e.g., Iio 1996). It is supposed that fluids play an important role in the microearthquake activity; however, the reason for the continuously occurring microearthquakes is not well understood.

Waveforms of microearthquakes that occur in this district show distinct reflected $\mathrm{S}$ waves $(\mathrm{S} \times \mathrm{S})$ about $10 \mathrm{~s}$ after the direct $\mathrm{P}$ waves (Katao 2002). Katao et al. (2007) conducted a reflection analysis and estimated the distribution of $\mathrm{S}$ wave reflection points using data observed at 10 permanent stations. They found a planar distribution

*Correspondence: sho.a@rcep.dpri.kyoto-u.ac.jp Graduate School of Science, Kyoto University, Kyoto, Japan of the $\mathrm{S}$ wave reflection points (S wave reflector) at a depth of 20-30 km. Also in this district, Nishigami (2007) estimated the distribution of scattering coefficients in the crust with a coda-wave inversion analysis (Nishigami 1991) and found a zone of high scattering coefficients distributed at depths of $20-30 \mathrm{~km}$.

$\mathrm{S}$ wave reflectors are also found in other regions in Japan. For example, Matsumoto and Hasegawa (1996) found that $S$ wave reflectors distribute in the mid-crust beneath Nikko-Shirane volcano in northeastern Japan. They estimated that the reflectors are two very thin layers with low $\mathrm{S}$ wave velocities. The total thickness of these reflectors is about $0.1 \mathrm{~km}$. It is inferred from this fact that the reflector body contains liquid material such as magma or water. Umino et al. (2002) estimated the location of reflectors using the seismograms of aftershocks of the 1998 M5.0 Sendai earthquake. They showed that a clear reflector is located at a depth of $15-21 \mathrm{~km}$ just beneath the fault plane of the earthquake (NagamachiRifu fault), and supposed that it is related to fluids. These reflectors are located at relatively shallow depths; however, $\mathrm{S}$ wave reflectors in the northern Kinki district seem 


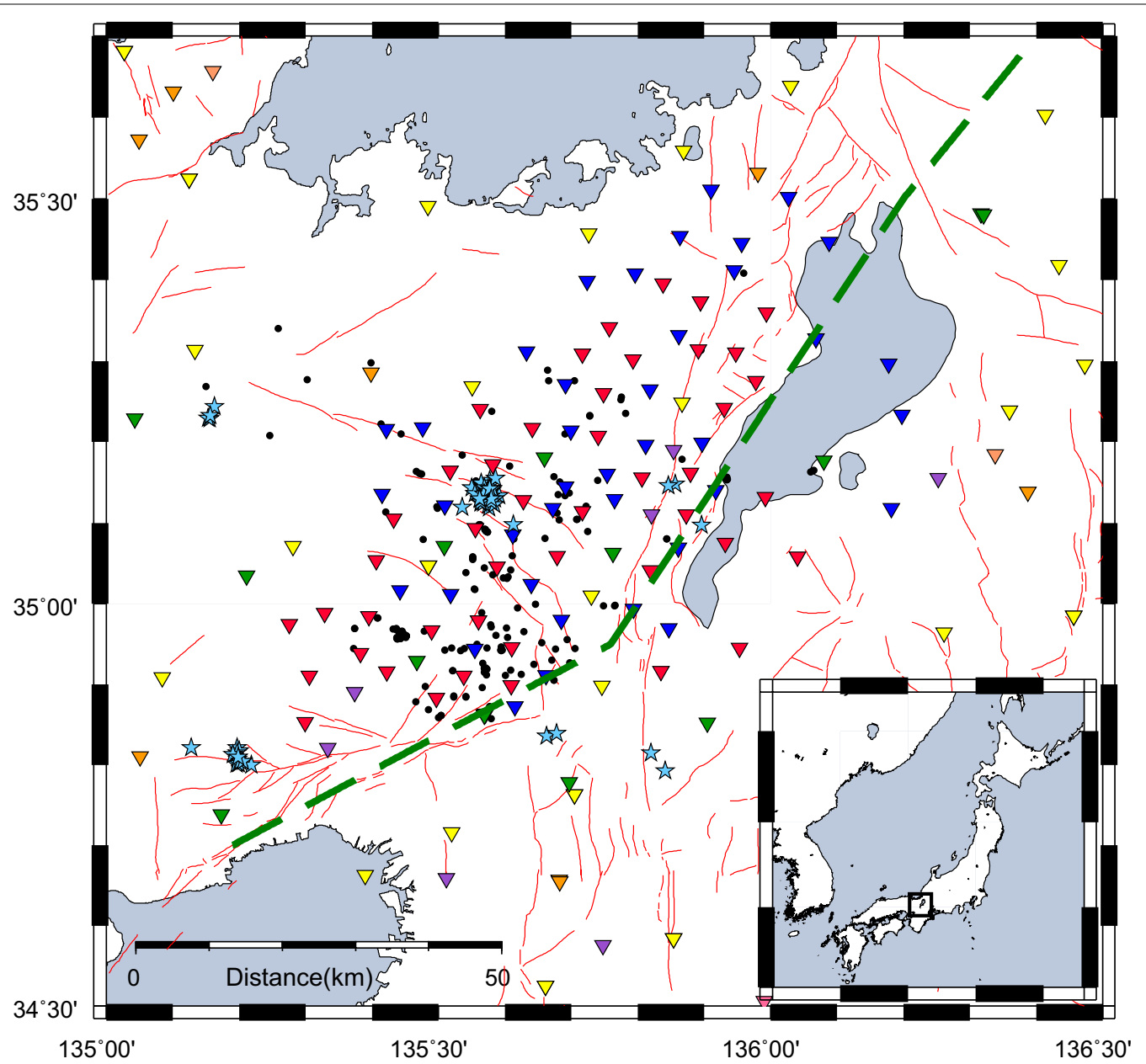

Fig. 1 Map showing the seismic stations and the hypocenters used in this study. Black dots represent 182 hypocenters used in this analysis. Green, purple, yellow, orange and red and blue reverse triangles represent permanent stations of Kyoto University, AIST, NIED and JMA, and temporary stations of Kyoto University, respectively. Light blue stars and red lines indicate hypocenters of low-frequency earthquakes (LFEs) and active faults, respectively. Green dashed line indicates NKTZ shown in Hyodo and Hirahara (2003)

to be located at greater depths than those beneath NikkoShirane volcano and the Nagamachi-Rifu fault. Doi and Nishigami (2007) estimated the three-dimensional distributions of $\mathrm{S}$ wave reflectors in the source region of the 2000 Western Tottori Earthquake. They reported three reflection zones exist beneath the source region, which are located at depth of $15-25,30-40$ and $50-60 \mathrm{~km}$ (Doi and Nishigami 2007). They proposed that the first and second reflectors are corresponding to the Conrad and the Moho discontinuities, respectively. Moreover, they discussed the relationship between the reflection strength in the source region and deep low-frequency earthquakes occurred beneath the source region of this earthquake. They reported the reflection strength is relatively high around the source region of the deep low-frequency earthquakes and suggested the existence of fluids.
In the northern Kinki district, a dense temporary seismic network has been operating since 2009 using the "Manten" system (Miura et al. 2010) with an average station spacing of about $5 \mathrm{~km}$. Thus, we can investigate crustal structure with high resolution using data from this dense temporary seismic network combined with the permanent network. In this study, we used data from these stations to estimate the detailed distributions of $\mathrm{S}$ wave reflectors.

\section{Data and analysis method}

In the northern Kinki district, there are 40 permanent short-period high-sensitivity seismometers and 88 temporary seismic stations within an area of about $70 \times 70 \mathrm{~km}^{2}$ (Fig. 1). We used waveforms obtained from these stations from February 2009 to February 2011. 
We manually checked waveforms of microearthquakes recorded at two permanent seismic stations of Kyoto University, DP.YGI and DP.KHK, and selected 182 earthquakes that show clear reflected waves. These earthquakes have magnitudes of M2.0 or greater. We show an example of waveforms observed at DP.YGI in Fig. 2. Reflected S waves are seen clearly about $6 \mathrm{~s}$ after the $\mathrm{S}$ wave onset on both the EW and NS components.

In this analysis, we used the stacking method by Doi and Nishigami (2007) which was based on the analyses of Inamori et al. (1992). Inamori et al. (1992) assume that coda waves after direct $\mathrm{S}$ waves are composed of $\mathrm{S}$ waves reflected at horizontal planes, and convert travel times of coda waves to depths of reflectors. Doi and Nishigami (2007) modified the method of Inamori et al. (1992) by using a normal moveout (NMO) correction for aligning aftershock waveforms. Doi and Nishigami (2007) estimated a three-dimensional distribution of reflectors by stacking the energies of reflected waves after the NMO correction.

In this analysis, the two horizontal components were converted to the transverse direction and a $5-8 \mathrm{~Hz}$ band pass filter was applied, because the dominant

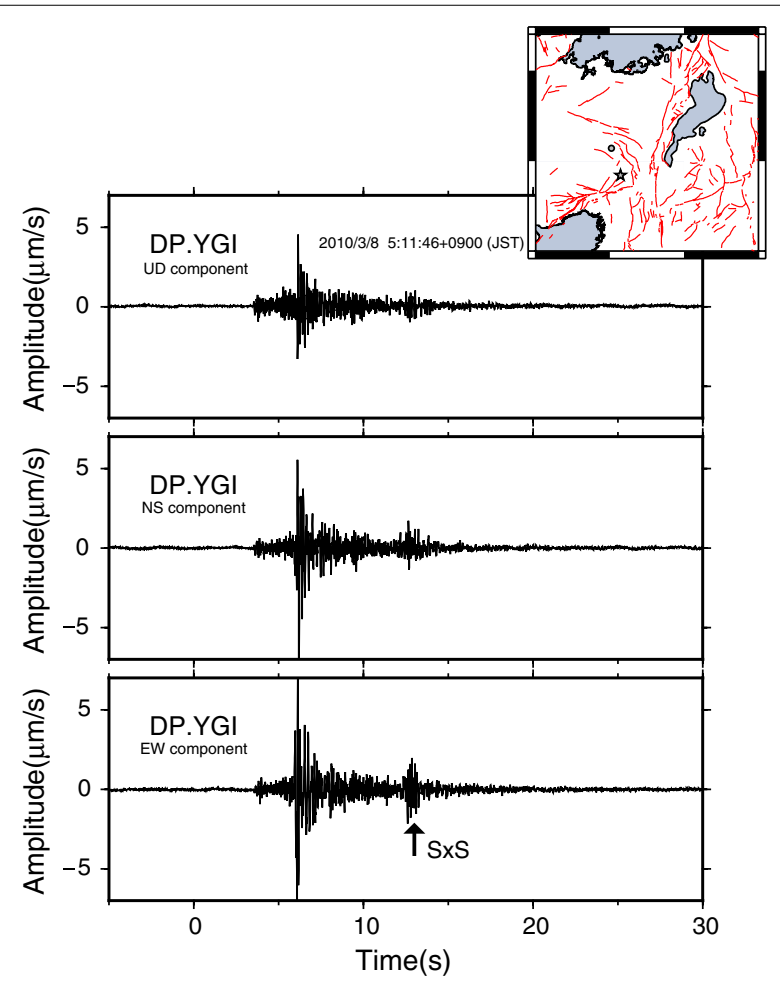

Fig. 2 Example of waveforms on USD, NS and EW components observed at DP.YGI. In the inset map, the star represents the epicenter of a M2.0 earthquake on March 8, 2010, and the circle indicates the seismic station (DP.YGI). Red lines indicate active faults (Nakata and Imaizumi 2002). Reflected waves indicated as S $\times$ S are seen about $6 \mathrm{~s}$ after from the $\mathrm{S}$ wave onset frequency of the reflected wave is $5-8 \mathrm{~Hz}$. Then, we corrected amplitudes of coda waves by assuming a coda- $Q$ $\left(Q_{C}\right)$ with the amplitudes $(A(t))$ given by the following expression,

$$
A(t)=\frac{1}{t} \exp \left(\frac{-2 \pi f t}{Q_{\mathrm{C}}}\right)
$$

where $t$ is the elapsed time from the occurrence of the earthquake, $f$ is the frequency and $Q_{\mathrm{C}}$ is the attenuation factor of the coda waves. We calculated $Q_{C}$ for each waveform by a least-squares fit of Eq. 1 to the coda amplitudes, using a time window of $30 \mathrm{~s}$ starting at the time after the origin time which corresponds to twice the $S$ wave travel time. $Q_{C}$ values for individual traces take values of $300-600$ in our analysis. We obtained an average $Q_{\mathrm{C}}=450$ by averaging all the estimated $Q_{\mathrm{C}}$ values and used this value to correct the coda amplitudes. By correcting amplitudes of waveforms by the above expression, we can emphasize the reflected waves. We conducted similar analyses using $Q_{\mathrm{C}}=300$ and $Q_{\mathrm{C}}=600$ and confirmed that there are no significant differences for the results for this range of assumed $Q_{C}$ values. We also applied the coda normalization method (Aki 1980) to correct amplitudes between different traces. Because waveforms in the period of 25-28 s after the origin time did not include large phases, we averaged amplitudes in this time window to normalize the waveforms. Furthermore, the waveforms were converted into the envelopes. The envelope $F(t)$ is formed from the real seismic trace $f(t)$ and the Hilbert transformed trace $f^{*}(t)$, as follows,

$$
F(t)=\left[f^{2}(t)+f^{* 2}(t)\right]^{1 / 2}
$$

For details, see Taner et al. (1979). In order to avoid the effect of the direct $S$ waves, we used only the envelopes starting at times after the origin time that correspond to twice the $\mathrm{S}$ wave travel time.

For calculating the three-dimensional distribution of the $\mathrm{S}$ wave reflections, we set $X, Y$ and $Z$ axes as parallel to latitude, longitude and the vertical directions, respectively. The size of the analysis area is $300 \mathrm{~km}$ along the $X$ axis, $300 \mathrm{~km}$ along the $Y$ axis and $60 \mathrm{~km}$ along the $Z$ axis, and its center is the point $\left(\mathrm{N} 35.2^{\circ}, \mathrm{E} 135.7^{\circ}\right)$. This analysis area is sufficiently larger than the distribution of the seismic stations and hypocenters of earthquakes used in this study. We divided the analysis area into 2,400,000 blocks with an interval of $1.5 \mathrm{~km}$ along the $X$ and $Y$ axes and $1 \mathrm{~km}$ along the $Z$ axis. We assumed an $S$ wave velocity of $3.5 \mathrm{~km} / \mathrm{s}$ and assigned envelope amplitudes to appropriate blocks by the NMO correction. Thus, the wavelengths of $S$ waves used in this study are about $400-700 \mathrm{~m}$. Then, we stacked relative envelope amplitudes and averaged them for each block. We defined the averaged value for 
each block as the reflection strength. Furthermore, we evaluated the confidence of the results by the number of data for each block. The number of data is calculated as a sum of the sampling data points of waveform envelopes assigned for a block by the NMO correction. When $S$ waves pass through a block vertically, a block includes about 71 data points for one trace, because the sampling frequency of the "Manten" system is $250 \mathrm{~Hz}$, the $\mathrm{S}$ wave velocity is $3.5 \mathrm{~km} / \mathrm{s}$, and the vertical block size is $1 \mathrm{~km}$. For example, a number of data of 10,000 means that about 140 traces are assigned to that block.

\section{Results}

We projected reflection strengths onto the NS and EW vertical planes and horizontal plane in Figs. 3, 4 and 5, respectively. A value of reflection strength of 1 is equal to the averaged reflection strength in blocks that correspond to the reference time window for the coda normalization. In these figures, we show the number of data assigned each block, in order to evaluate the reliability of the results. In the inset map of Figs. 3 and 4, we contoured the number of data at depth of $26 \mathrm{~km}$ with a thick blue line for 50,000 and thin blue lines for contour intervals of 2000. The number of data is related to the number of traces that pass through the block. Although we show results for all the blocks where reflection strengths are calculated, here we will only discuss the blocks with the number of data more than 10,000, enclosed by blue lines in each section, because the number of the data decreases quickly in the area of those less than 10,000, as shown in Figs. 3 and 4.

In Figs. 3 and 4, we show hypocenters of ordinary earthquakes and low-frequency earthquakes (LFEs, determined by JMA) that occurred in 2009-2011, regardless of magnitudes. Hypocenters shown in the sections are located within $5 \mathrm{~km}$ from each section. In Fig. 5, we show the hypocenters of LFEs regardless of magnitudes and depths. In Figs. 3 and 4, reflection strengths at the depth of $40 \mathrm{~km}$ are nearly the same, because of the effect of the coda normalization.

We show the results for NS vertical planes in Fig. 3a-e. It seems that the zone of high reflection strengths (R1) becomes deeper northward in Fig. $3 \mathrm{a}-\mathrm{c}$ and that LFEs occurred near the northern edge of the zone in Fig. 3b. In Fig. 3a $(X=-23.25)$, a zone of high reflection strengths (higher than 1.5) is located at depths of $25-28 \mathrm{~km}$ in the central part of R1, and zones of moderately high reflection strengths (higher than 1.2) are distributed around the zone of high reflection strengths. In Fig. 3b $(X=-12.75)$, a zone of high reflection strengths is located at depths of 23-30 km (R1). In Fig. 3c ( $X=-3.75)$, a zone of high reflection strengths is located at depths of $21-28 \mathrm{~km}$ (R1), and a zone of moderately high reflection strengths becomes deeper northward (R1), similar to that in
Fig. 3b. In Fig. 3e $(X=15.75)$, a zone of high reflection strengths is located at depths of $28-32 \mathrm{~km}$ (R4), and LFEs occur near these high reflection strengths. There are small patches of moderately high reflection strengths at depths of 24-27 and 32-34 km (R2 and R3) in Fig. 3c, at 26-29 km (R4) and 32-35 km (R5) in Fig. 3d.

In the EW vertical planes shown in Fig. 4a-e, it is seen that a zone of high reflection strengths (R1) becomes deeper to the north at $X=-20$ to -0 in Fig. $4 \mathrm{~b}-\mathrm{e}$. Around the hypocenters of LFEs in Fig. 4B, a zone of moderately high reflection strengths is seen down to a depth of about $35 \mathrm{~km}$. Other zones of high reflection strengths are seen at $X=10$ (R4) in Fig. 4a-c, and LFEs occurred near the patch at $X=15$, as shown in Fig. 4b.

These features are clearly seen in the horizontal section shown in Fig. 5a-f. Depths of the zone of high reflection strengths become deeper to the north, and they are deepest around the epicenters of LFEs around $X=-15$ and $Y=-5$.

\section{Discussions}

As mentioned above, we set the analysis area of $300 \times 300 \times 60 \mathrm{~km}$ with the center $\left(\mathrm{N} 35.2^{\circ}, \mathrm{E} 135.7^{\circ}\right)$, and this area is sufficiently larger than the distribution of the seismic stations and the hypocenters used in this study. However, we do not discuss the results obtained for blocks that have the number of the data less than 10,000, because the number of the data decreases quickly in the area of blocks of less than 10,000, as shown in Figs. 3 and 4 , and it is difficult to compare results obtained at blocks with a large difference in the number of data.

In this study, we found a zone of distinct north dipping high reflection strengths at depths of $21-30 \mathrm{~km}(\mathrm{X}=-20$ to $0, Y=-35$ to 3 ), which we call the $\mathrm{S}$ wave reflector. We calculated the averaged value and standard deviation of reflection strengths using the data for all the blocks, where reflection strengths were obtained. Then, we found that the reflection strengths in the $\mathrm{S}$ wave reflector are within one standard deviation $(\sigma)$ from the mean value. Katsumata (2010) reported the depth of the Moho and the Conrad discontinuities beneath the Japanese islands. According to Katsumata (2010), the Conrad discontinuity exists at depth of $15-20 \mathrm{~km}$ in this district. Therefore, it is thought that the high reflection strengths zone is not the Conrad discontinuity. We also found small zones of high reflection strengths at depths of 32-34 km (R3), 28-32 km (R4) and 32-35 km (R5). Katsumata (2010) estimated the depth of the Moho discontinuity is deeper than $34 \mathrm{~km}$ near these zones. Since these zones are basically located deeper than the Moho discontinuity and the extents of these zones are limited in small portions, it is likely that these zones do not reflect the Moho discontinuity but heterogeneities in the crust. 

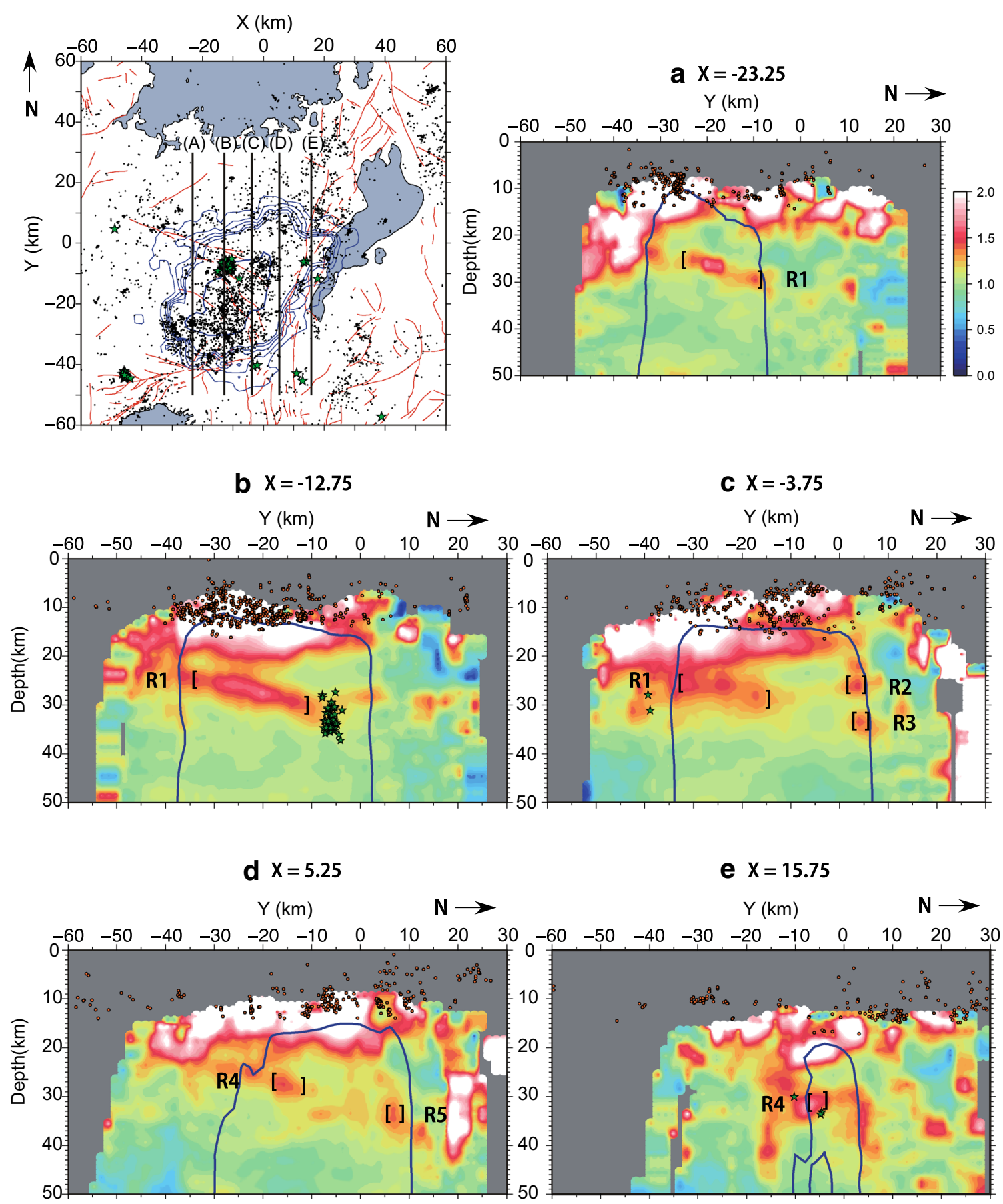

Fig. 3 Reflection strengths along NS vertical planes $[X=-23.25(\mathbf{a}),-12.75(\mathbf{b}),-3.75(\mathbf{c}), 5.25(\mathbf{d})$, and $15.75(\mathbf{e})]$. The color scale is shown in the upper right side. Locations of the planes are shown in the map on the upper left side. In the map, contours show the number of data at depth of $26 \mathrm{~km}$ assigned to each block. Thick blue lines show contours for 50,000, and thin blue lines are for contour intervals of 2000. When we draw contours, we interpolate the number of data. Black dots, green stars and red lines indicate hypocenters of ordinary earthquakes and low-frequency earthquakes (LFEs), and active faults, respectively. In the vertical planes, hypocenters occurring within $5 \mathrm{~km}$ of each plane are plotted, and blue lines indicate the contours of 10,000 for the number of data

Ito et al. (2006) carried out the refraction and wideangle reflection surveys by controlled sources and found some reflectors. They reported that the reflector existed at depth of $20-30 \mathrm{~km}$ and LFEs occurred beneath this reflector. The location and depth of this reflector correspond to those of the $\mathrm{S}$ wave reflector in this analysis. 

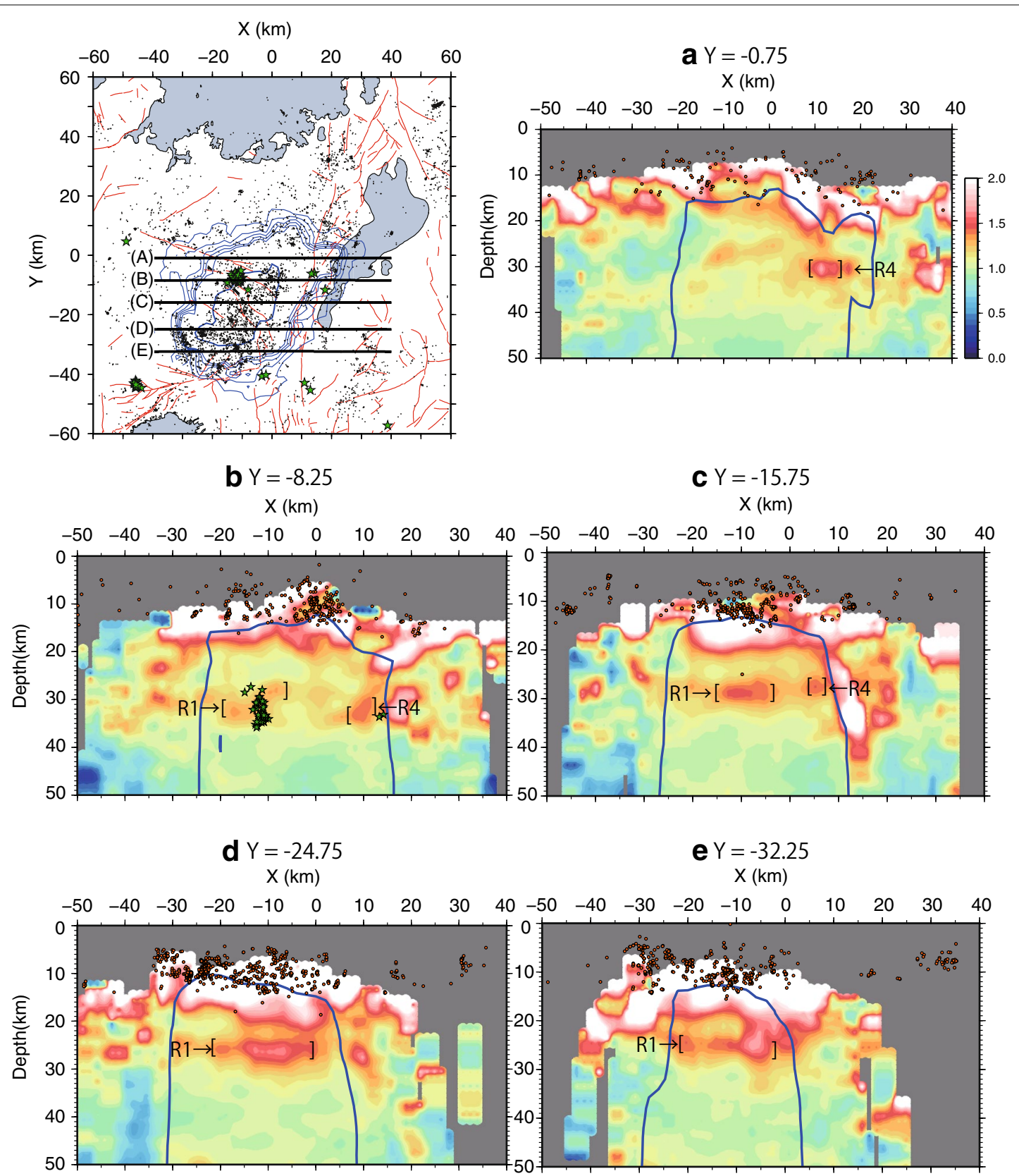

Fig. 4 Reflection strengths along EW vertical planes $[Y=-0.75(\mathbf{a}),-8.25(\mathbf{b}),-15.75(\mathbf{c}),-24.75(\mathbf{d})$ and $-32.25(\mathbf{e})]$. The other explanations are the same as in Fig. 3

Katao et al. (2007) used a mirror-imaged station method with onset times of $\mathrm{S} \times \mathrm{S}$ phases and first found that $\mathrm{S}$ wave reflection points are dipping to the north. The result of Katao et al. (2007) is in accordance with the high reflection strengths zone estimated in this study at depth of $25-30 \mathrm{~km}$. However, the reflected points estimated by Katao et al. (2007) are more widely scattered than the $S$ wave reflector estimated by this study, probably due to uncertainties of $\mathrm{S} \times \mathrm{S}$ onset times. In this study, it is not necessary to pick onsets of $\mathrm{S} \times \mathrm{S}$ phases. Furthermore, this analysis has an advantage that $3 \mathrm{D}$ distributions of relative reflection strengths are objectively determined by the waveform stacking.

A very large impedance contrast, in particular an $S$ wave velocity contrast, is necessary to produce distinct $\mathrm{S}$ wave reflectors. Thus, it is expected that fluid is concentrated in the high reflection strengths zone. This expectation is supported by the fact that LFEs 

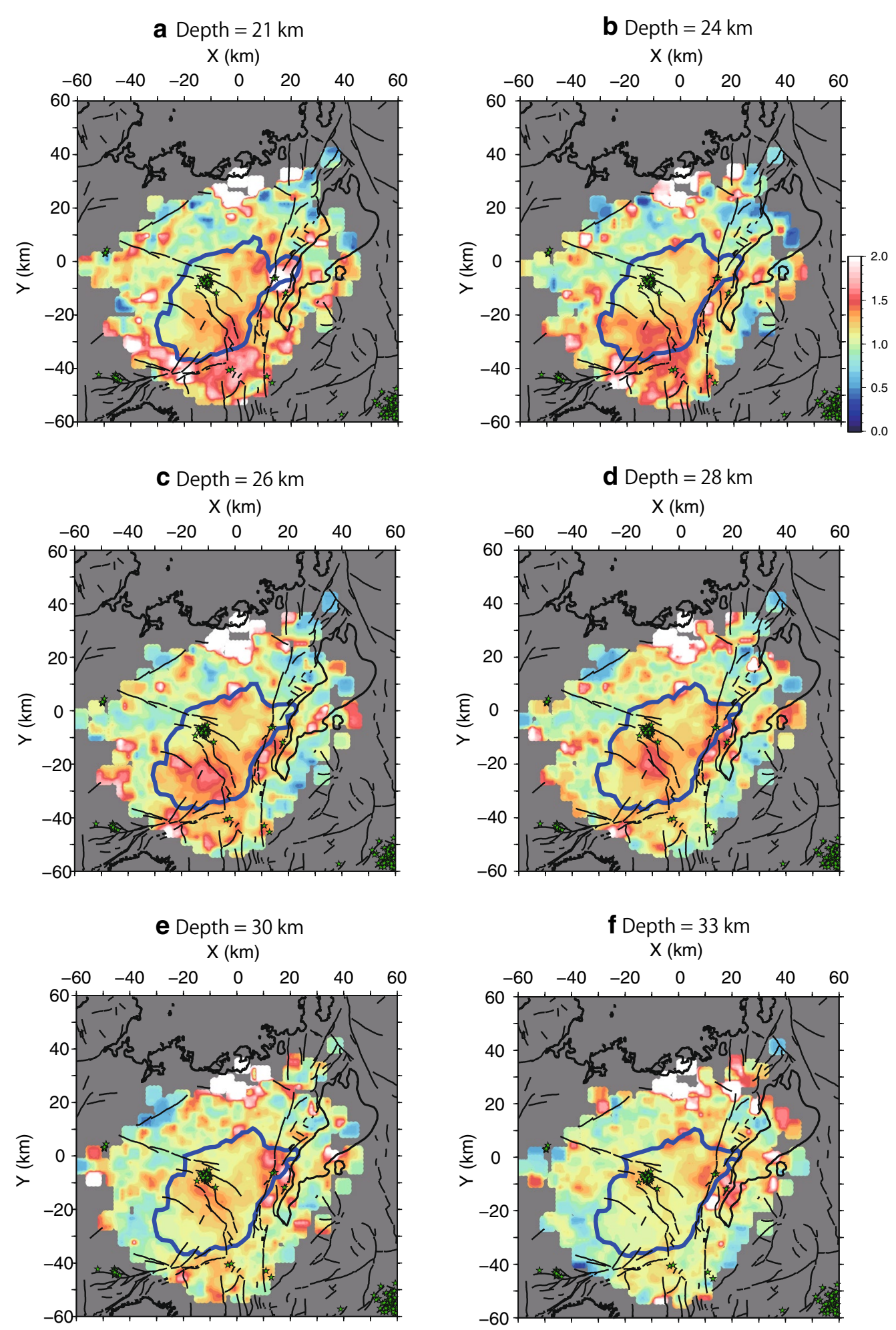

Fig. 5 Reflection strengths on horizontal planes [depth $=21(\mathbf{a}), 24(\mathbf{b}), 26(\mathbf{c}), 28(\mathbf{d}), 30(\mathbf{e})$ and $33(\mathbf{f}) \mathrm{km}$ ]. Hypocenters of LFEs are plotted regardless of magnitudes and depths. Black lines indicate active faults. Blue lines indicate the contours of 10,000 for the number of data 
occur near the lower edge of the $\mathrm{S}$ wave reflector, and reflection strengths are slightly larger around the hypocenters of LFEs, as shown in Fig. 4b. Furthermore, LFEs occurred near the other zone of high reflection strengths at depths around the Moho discontinuity, as shown in Fig. 3e. It is likely that the high reflection strengths zone is a fluid path from the mantle, together with the hypocentral region of the LFEs. Takahashi and Miyamura (2009) reported the occurrences of LFEs in Japanese islands. They suggested that LFEs in the northern Kinki region occur around depth of $30 \mathrm{~km}$, near the Moho discontinuity, and that they are related to fluid dehydrated from the subducting Philippine Sea plate. According to Isozaki et al. (2010), there is no stranded slab related to the paleo-subduction. Thus, dehydrated fluid is thought to relate to the current subduction. However, the strengths of the reflections are not clear around the upper edge of the $\mathrm{S}$ wave reflector, because of lack of data. In addition, it is seen that many microearthquakes occur above the reflector; however, the relationship between this activity and the $\mathrm{S}$ wave reflector is not well understood by the present study.

Iio et al. (2002) proposed a model of strain concentration in the NKTZ, in which the lower crust is weakened by water upwelling from the subduction plates. If their model holds, it is thought that the lower crust in the northern Kinki district has a higher fluid content than the surrounding region, because the northern Kinki district is a part of the NKTZ. This consideration is in accordance with the results obtained in this study.

\section{Conclusion}

By using waveforms from a dense seismic network, we estimated the distribution of the zones of high reflection strengths (S wave reflectors) at depths of $25-30 \mathrm{~km}$ in the northern Kinki district. We found a zone of high reflection strengths dipping to the north and that lowfrequency earthquakes (LFEs) occurred near the edges of the zone at depths around the Moho discontinuity. It is inferred from these results that fluid is concentrated in this zone of high reflection strengths. It is likely that the zones of high reflection strengths are fluid paths from the mantle, together with the hypocentral region of the LFEs, located near the $\mathrm{S}$ wave reflector.

\section{Authors' contributions}

SA carried out the data processing and drafted the manuscript. YI and HK maintained the seismic stations and helped draft the manuscript. TM, IY and MS maintained the seismic stations and supervised the data. All authors read and approved the final manuscript.

\section{Acknowledgements}

We are thankful to two anonymous reviewers for useful comments and suggestions to improve this manuscript. This study was partly supported by the Earthquake and Volcano Hazards Observation and Research Program, and the Multidisciplinary research project for high strain rate zone of the Ministry of Education, Culture, Sports, Science and Technology (MEXT), Japan, and the MEXT KAKENHI Grant Number 26109006. We would like to thank I. Doi for providing us with the stacking program. We also thank James Mori for his thoughtful comments and suggestions. We used seismic data from the National Research Institute for Earth Science and Disaster Prevention (NIED), the National Institute of Advanced Industrial Science and Technology (AIST), the Japan Meteorological Agency (JMA) and Kyoto University. Figures were drawn by GMT (Wessel and Smith 1991).

\section{Competing interests}

The authors declare that they have no competing interests.

Received: 1 January 2016 Accepted: 10 May 2016

Published online: 24 June 2016

\section{References}

Aki K (1980) Attenuation of shear-waves in the lithosphere for frequencies from 0.05 to $25 \mathrm{~Hz}$. Phys Earth Planet Inter 21:50-60

Doi I, Nishigami K (2007) Three-dimensional distributions of S wave reflectors in the source region of the 2000 Western Tottori Earthquake. Geophys Res Lett 34:L20312. doi:10.1029/2007GL031169

Hyodo M, Hirahara K (2003) A viscoelastic model of interseismic strain concentration in Niigata-Kobe Tectonic Zone of central Japan. Earth Planets Space 55:667-675

lio Y (1996) A possible generating process of the 1995 Southern Hyogo prefecture earthquake-stick of fault and slip on detachment—Zisin. J Seismol Soc Japan 2(49):103-112 (in Japanese)

lio Y, Sagiya T, Kobayashi Y, Shiozaki I (2002) Water-weakened lower crust and its role in the concentrated deformation in the Japanese Islands. Earth Planet Sci Lett 203:245-253

Inamori T, Horiuchi S, Hasegawa A (1992) Location of mid-crustal reflectors by a reflection method using aftershock waveform data in the focal area of the 1984 Western Nagano prefecture earthquake. J Phys Earth 40:379-393

Isozaki Y, Aoki K, Nakama T, Yanai S (2010) New insight into a subductionrelated orogen: a reappraisal of the geotectonic framework and evolution of the Japanese Islands. Gondwana Res 18:82-105

Ito K, Umeda Y, Sato H, Hirose I, Hirata N, Kawanaka T, Ikawa T (2006) Deep seismic surveys in the Kinki district: Shigu-Maizuru line. Bull Earthq Res Inst Univ Tokyo 81:239-245

Katao H (2002) Seismicity of Tamba region. Chikyu Mon extra 38:42-49 (in Japanese)

Katao H, Ito K, Nakao S, Hirose I, Nishimura K, Fukushima M (2007) Seismic survey on the deep reflector beneath the Tamba Plateau. Ann Disaster Prev Res Inst Kyoto Univ 50(B):297-302 (in Japanese)

Katsumata A (2010) Depth of the Moho discontinuity beneath the Japanese islands estimated by traveltime analysis. J Geophys Res 115:B04303. doi:1 $0.1029 / 2008 J$ J005864

Matsumoto S, Hasegawa A (1996) Distinct S wave reflector in the midcrust beneath Nikko-Shirane volcano in the northeastern Japan arc. J Geophys Res 101(B2):3067-3083

Miura T, lio Y, Katao H, Nakao S, Yoneda I, Fujita Y, Kondo K, Nishimura K, Sawada M, Tada M, Hirano N, Yamazaki T, Tomisaka K, Tatsumi K, Kamo M, Shibutani T, Ohmi S, Kano Y (2010) Temporary Seismic Observation in the Northern Kinki District. Ann Disaster Prev Res Inst Kyoto Univ 53(B):203212 (in Japanese)

Nakata T, Imaizumi T (2002) Digital active fault map of Japan. University of Tokyo Press, Tokyo

Nishigami K (1991) A new inversion method of coda waveforms to determine spatial distribution of coda scatterers in the crust and uppermost mantle. Geophys Res Lett 18:2225-2228

Nishigami K (2007) Heterogeneous structure in the crust estimated from inversion analysis of coda envelopes. Chikyu Mon 29(4):222-226 (in Japanese) 
Sagiya T, Miyazaki S, Tada T (2000) Continuous GPS array and present-day crustal determined of Japan. Pure appl Geophys 157:2303-2322

Takahashi H, Miyamura J (2009) Deep low-frequency earthquakes occurring in Japanese Islands. Geophys Bull Hokkaido Univ 72:177-190

Taner MT, Koehler F, Sheriff RE (1979) Complex seismic trace analysis. Geophysics 44(6):1041-1063
Umino N, Ujikawa H, Hori S, Hasegawa A (2002) Distinct S-wave reflectors (bright spots) detected beneath the Nagamachi-Rifu fault, NE Japan. Earth Planets Space 54:1021-1026

Wessel P, Smith WHF (1991) Free software helps map and display data. EOS Trans AGU 72:441

\section{Submit your manuscript to a SpringerOpen ${ }^{\circ}$ journal and benefit from:}

- Convenient online submission

- Rigorous peer review

- Immediate publication on acceptance

- Open access: articles freely available online

- High visibility within the field

- Retaining the copyright to your article 